Kong. Res. J. 2(1) : 118-120, 2015

ISSN 2349-2694

Kongunadu Arts and Science College, Coimbatore.

\title{
STANDARDIZATION OF MEDIUM FOR SYNTHETIC SEED GERMINATION OF SALVIA SCLAREA L.
}

\author{
Durgha.H., G. Ramya, M. Gogul Ramanth and R. Thirugnanasampandan* \\ PG and Research Department of Biotechnology, Kongunadu Arts and Science College, Coimbatore \\ *E.mail: rtsampandan@yahoo.com
}

\begin{abstract}
Young nodal explants $(0.5-1 \mathrm{~cm})$ of Salvia sclarea L. was used for synthetic seed preparation. Synthetic seeds were prepared using $5 \%$ sodium alginate and $1.11 \%$ calcium chloride. Seed germination was observed on MS medium fortified with $1.4 \mu \mathrm{M} \mathrm{GA3}+4.4 \mu \mathrm{M}$ BA after twenty days of culture. Further multiple shoot induction was observed after fifteen days of shoot induction.
\end{abstract}

Keywords: Synthetic seed, sodium alginate, calcium chloride

\section{INTRODUCTION}

Salvia the largest genus in the family Lamiaceae contains more than 1000 species distributed mainly in Central and South America (500 sp.), Central Asia/Mediterranean (250 sp.) and Eastern Asia (100 sp.). Most species are perennial herbs but annuals, shrubs, a few trees and vines also exist (Alziar, 1993). The name Salvia comes from two latin words "salvare" meaning "to heal" and "salveo" which means "to save" or "to recover" (Aktas et al., 2009). Like other members of Lamiaceae, Salvia species are aromatic and rich in essential oils which have been used in food, cosmetics, perfumes and pharmaceuticals (Baratta et al., 1998).

Salvia sclarea L. an aromatic perennial herb belonging to Lamiaceae is considered economically and one of the most cultivated species for medicinal purpose and extraction of active constituents (Pierik, 1987). The plant is known for its high value essential oil, the oil is used to reduce stress, tension, depression, insomnia and wild colic etc (Grieve, 1974). Traditionally $S$. sclarea has been used to promote blood circulation, remove stagnation, tranquilize the mind, clear heat from the blood and resolves swelling. The most important and frequent clinical use has been in the treatment of coronary heart disease for the alleviation of angina pectoris, coronary artery spasm and myocardial infarction (Zhou et al., 2005).

Since poor seed set and germination leads to the extinction of such valuable species. So the present study was aimed to prepare the synthetic seed using nodal explants for immediate regeneration and storage for long term use.

\section{MATERIALS AND MEHODS}

\subsection{Collection of plant material}

The leaves of Salvia sclarea L. was collected from Cinchona, Nilgiri hills, Tamil Nadu, India

\subsection{Explant selection and mode of sterilization}

Nodal explant was collected from actively growing plants and washed thoroughly in running tap water followed by Teepol treatment for 5-10 min. The explants were subsequently surface sterilized with $0.01 \%(\mathrm{w} / \mathrm{v})$ mercuric chloride solution for 2-3 min and washed 3-4 times with sterile double distilled water for duration of $15 \mathrm{~min}$ with an interval of five min for each wash.

\subsection{Method of medium preparation}

MS (Murrashige and Skoog, 1962) medium was employed in the present study and the composition of the medium is given in Table- 1 . The nutrient medium basically consists of inorganic salts, carbon source, vitamins and amino acids. Stock solutions were prepared separately for macronutrients, micronutrients, iron, potassium iodide and vitamins. All the chemicals were weighed accurately in electronic weighing machine. All the stock solutions were poured into well stoppered sterilized bottles and preserved in a refrigerator at $4^{\circ} \mathrm{C}$. Specific quantity of the stock solutions and growth regulators were pipetted onto a little beaker. The final volume was made up with distilled water.

Table 1. Chemical composition of MS medium (Murashige and Skoog, 1962)

\begin{tabular}{lll}
\hline S.NO & Components & mg/L \\
\hline Major salts & & \\
1. & $\mathrm{NH}_{4} \mathrm{NO}_{3}$ & 1650 \\
2. & $\mathrm{KNO}_{3}$ & 1900 \\
3. & $\mathrm{CaCl}_{2} \cdot 2 \mathrm{H}_{2} \mathrm{O}$ & 440
\end{tabular}




\begin{tabular}{lll}
4. & $\mathrm{MgSO}_{4} \cdot 7 \mathrm{H}_{2} \mathrm{O}$ & 370 \\
5. & $\mathrm{KH}_{2} \mathrm{PO}_{4}$ & 170 \\
Minor salts & & \\
6. & $\mathrm{KI}$ & 0.83 \\
7. & $\mathrm{H}_{3} \mathrm{BO}_{3}$ & 6.20 \\
8. & $\mathrm{MnSO}_{4} 4 \mathrm{H}_{2} \mathrm{O}$ & 22.3 \\
9. & $\mathrm{ZnSO}_{4} .7 \mathrm{H}_{2} \mathrm{O}$ & 8.6 \\
10. & $\mathrm{Na}_{2} \mathrm{Mo}_{4} .2 \mathrm{H}_{2} \mathrm{O}$ & 0.25 \\
11. & $\mathrm{CuSO}_{4} .5 \mathrm{H}_{2} \mathrm{O}$ & 0.025 \\
12. & $\mathrm{CoCl}_{2} \cdot 6 \mathrm{H}_{2} \mathrm{O}$ & 0.025 \\
13. & $\mathrm{Fe} / \mathrm{Na}^{-} \mathrm{EDTA}$ & 0.73 \\
Vitamins and & Organics & \\
14. & Myoinositol & 100 \\
15. & Thiamine $\mathrm{HCl}$ & 0.10 \\
16. & Pyridoxine $\mathrm{HCl}$ & 0.50 \\
17. & Nicotinic acid & 0.50 \\
18. & Glycine & 2.0 \\
19. & Agar & $8 \mathrm{~g}$ \\
20. & Sucrose & $30 \mathrm{~g}$ \\
21. & pH & 5.8 \\
\hline
\end{tabular}

To the above said medium, $3 \%$ sucrose was added and $\mathrm{pH}$ was adjusted to 5.8 with either $0.1 \mathrm{~N}$ $\mathrm{NaOH}$ or $0.1 \mathrm{~N} \mathrm{HCl}$ using a pH meter, further $0.8 \%$ agar was added, melted in a water bath and the medium was dispensed into $100 \mathrm{~mL}$ culture flask (50 $\mathrm{mL}$ medium) or to $25 \mathrm{~mL}(25 \times 150 \mathrm{~mm})$ test tubes (10-15 mL medium). The tubes or the flask after covering with cotton plug or screw caps were autoclaved at $1.06 \mathrm{~kg}$ pressure/sq $\mathrm{cm}$ for about 20 min at $121^{\circ} \mathrm{C}$. The autoclaved medium in the culture tubes were cooled and allowed to solidify as slants or straights and were stored at $25^{\circ} \mathrm{C}$ in the dark for future use. The inoculation was done after 5 days to ensure that the tubes were free from contamination.

\subsection{Artificial seed preparation}

For encapsulation purpose 5\% sodium alginate and $100 \mathrm{mM}$ calcium nitrate $(\mathrm{w} / \mathrm{v})$ were prepared using sterile distilled water. The nodes were transferred to the sodium alginate solution. The node along with sodium alginate was dropped into calcium nitrate solution and left for atleast $15 \mathrm{~min}$ for bead formation. The beads were recovered by discarding the sodium nitrate solution and washed twice with sterile distilled water.

\subsection{Culture medium and condition}

The encapsulated nodes were cultured on MS medium supplemented with various concentrations of cytokinins individually and in combination of BA + GA3. All cultures were maintained in the culture room at $25 \pm 2^{\circ} \mathrm{C}$ under $16 \mathrm{~h}$ photoperiod.

\section{RESULTS AND DISCUSSION}

\subsection{In vitro synthetic seed germination}

Synthetic seeds were prepared from the young and tender nodal explants of $S$. sclarea (Plate 1A). The inoculated synthetic seeds were germinated on
MS medium containing $1.4 \mu \mathrm{M} \mathrm{GA}_{3}$ and $4.4 \mu \mathrm{M}$ BA after 20 days of culture (Plate 1B). Further shoot induction, elongation and multiple shoot formation was observed on the same medium after 15 days of culture (Plate $1 \mathrm{C}$-D). The increasing demand for useful secondary metabolites has intensified the application of biotechnological methods to reproduce high yielding plants under controlled growing conditions and or to obtain homogenous and stable genotypes. A growing interest in the development of efficient protocols to micropropagate certain species of Salvia has also been increased (Arikat et al., 2004). In the present study, synthetic seeds were prepared using nodal explants of S.sclarea. Further the seeds were cultured on $\mathrm{GA}_{3}+\mathrm{BA}$ combination showed seed germination and shoot elongation. The shoot induction and elongation is associated with the presence of both $\mathrm{GA}_{3}$ and $\mathrm{BA}$, since both growth regulators are reported to be best suited for shoot induction and elongation for number plant species. $\mathrm{GA}_{3}+\mathrm{BA}$ and $\mathrm{GA}_{3}+$ kin showed marked effect on shoot induction from the nodal explants of Salvia officinalis (Pinarosa Avato et al., 2005). Young nodal segments of Salvia santolinifolia cultured on MS+BA (1-3mg/L) showed maximum number of shoot production (Javanmardi and Khalida, 2014). Rahmani et al. (2014) reported higher seed germination percentage in medium fortified with $\mathrm{GA}_{3}$ in Salvia sahendica and S. hypoleuca.
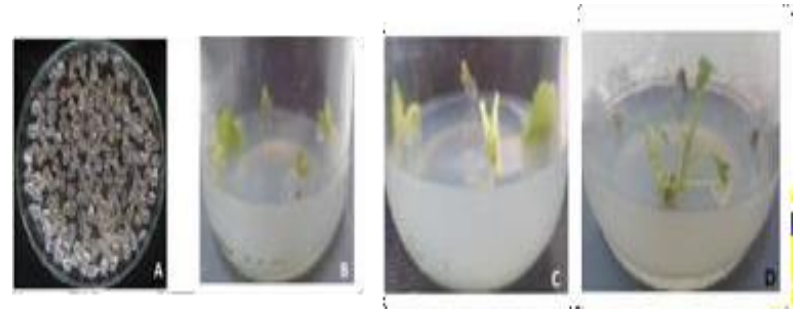

Plate 1:(A) Synthetic seeds prepared from nodal explants (B) Synthetic seed germination on MS medium supplemented with $1.4 \mu \mathrm{M}$ GA3 and 4.4 $\mu \mathrm{M}$ BA (C) Shoot induction on the same medium (D) Shoot elongation on the same medium after 15 days of culture

\section{CONCLUSION}

The present study revealed that 5\% soldium alginate and $100 \mathrm{mM}$ calcium chloride are best suited for synthetic seed preparation of salvia sclarea $\mathrm{L}$. and MS medium supplemented with $1.4 \mu \mathrm{M}$ GA3 and $4.4 \mu \mathrm{M}$ BA showed appreciable shoot induction from the synthetic seeds. 


\section{REFERENCES}

Aktas, K., C. Ozdemir, M. Ozkan, Y. Akyol and P. Baran, (2009). Anatomoical characteristics of Salvia tchihatcheffii endemic to Turkey. Afr. J. Biotechnol. 8(18): 4519-4528.

Alziar, G. (1993). Catalogue synonymique des Salvia L. du monde (Lamiaceae), I-VI. Biocosme Mesoge'en. 5:3-4, 87-136; 6:1-2, 4, 79-115, 163-204; 7:1-2, 59-109; 9:2-3, 413-497; 10:34, 33-117.

Arikat, N.A., F.M. Jawad, N.S. Karam, and R.A. Shibli, (2004). Micropropagation and accumulation of essential oils in wilde sage (Salvia fruticosa Mill.). Sci. Hort. 100: 193-202.

Baratta, M.T., H.J.D. Dorman, S.G. Deans, A.C. Figueiredo, J.G. Barroso and G. Ruberto, (1998). Antibacterial and anti-oxidant properties of some commercial essential oils. Flav. Frag. J. 13: 235-244.

Grive, M. (1974). A Modern Herbal, Jonathan Cape Ltd. 30- Bedford Square, London, 705-707.

Javanmardi, J., A. Khalighi, A. Kashi, H.P. Bais and J.M. Vivanco, (2002). Chemical characterization of
Basil (Ocimum basilicum L.) found in local accessions and used in traditional medicines in Iran. J. Agri. Food Chem. 50: 5878-5883.

Murashige, T. and F. Skoog, (1962). A revised medium for rapid growth and bio-assays with tobacco tissue cultures. Physiol. Pl. 15(3): 473497.

Pierik, R.L.M. (1987). In Vitro Culture of Higher Plants. Martinus Nijhoff, Dordrecht, The Netherlands.

Pinarosa Avato, Irene Morone Fortunato, Claudia Ruta. and Roberta D'Elia, (2005). Glandular hairs and essential oils in micropropagated plants of Salvia officinalis L. Pl. Sci. 169: (2005) 29-36.

Rahmani, M., Y. Hamidoghli and H. Zakizadeh (2014). Micropropagation of two Iranian endemic salvia species. Pl. cell biotechnol. Molecul. Biol. 15: 4350.

Zhou, L., Z. Zuo and M.S.S. Chow, (2005). Danshen: an overview of its chemistry, pharmacology, pharmacokinetics and clinical use. J. Clin. Pharmacol. 45: 1345-1359. 